
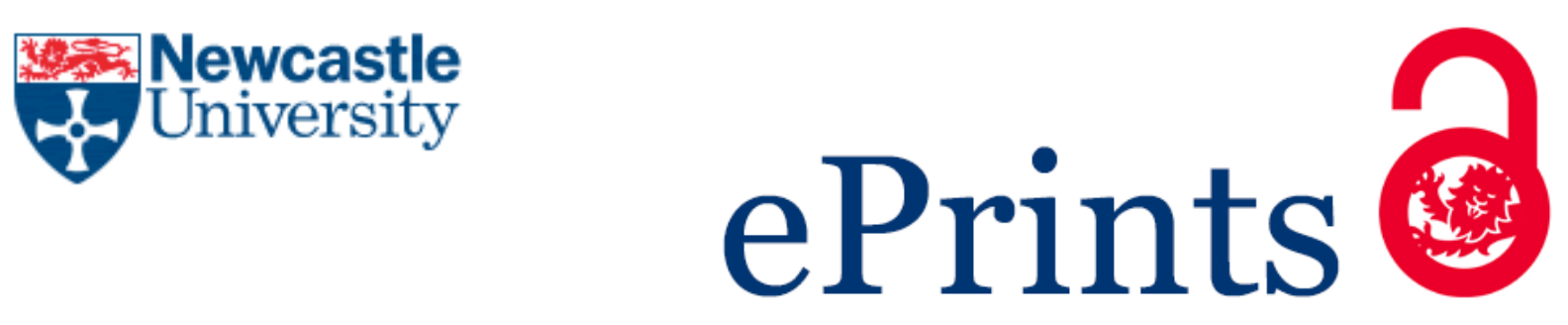

McKinnon I, Hayes A, Grubin D.

Health characteristics of older police custody detainees in London, UK.

The Journal of Forensic Psychiatry \& Psychology (2017)

DOI: http://dx.doi.org/10.1080/14789949.2017.1280071

\title{
Copyright:
}

This is an Accepted Manuscript of an article published by Taylor \& Francis in The Journal of Forensic Psychiatry \& Psychology on 23/01/2017, available online:

http://dx.doi.org/10.1080/14789949.2017.1280071.

Date deposited:

04/01/2017

Embargo release date:

23 January 2018

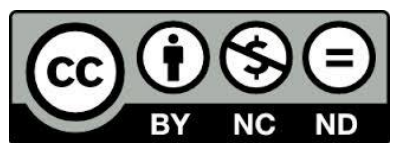

This work is licensed under a

Creative Commons Attribution-NonCommercial-NoDerivatives 4.0 International licence 


\section{Health characteristics of older police custody detainees in London, UK}

Dr lain McKinnon (corresponding).

Honorary Senior Clinical Lecturer, Institute of Health and Society, Newcastle University and Consultant Psychiatrist, Northumberland Tyne and Wear NHS Foundation Trust.

Academic Psychiatry, Campus for Ageing and Society, Westgate Road, Newcastle upon Tyne. NE4 5PT. iain.mckinnon@ncl.ac.uk

Dr Adrian Hayes.

Academic Clinical Fellow, Department of Psychiatry, Oxford University and Oxford Healthcare NHS Foundation Trust, Warneford Hospital, Oxford. OX3 7JX.

adrianjhayes@hotmail.com

Professor Don Grubin.

Emeritus Professor of Forensic Psychiatry, Institute of Neuroscience, Newcastle University.

don.grubin@ncl.ac.uk

Keywords

Older Detainees, Police Custody, Mental Health, Criminal Justice System, Hard to access populations 


\section{Abstract}

The number of older adults involved in the criminal justice system is rising. Little is known about the state of health in older people who are arrested. This study compared characteristics and healthcare needs of older police custody detainees with their younger counterparts. The health characteristics of 57 police detainees aged over 50 were compared with 543 younger detainees.

Older detainees had significantly higher rates of physical illness and risk of alcohol withdrawal. Although there were equivalent rates of mental disorder and drug taking compared with younger detainees, a higher proportion had presentations consistent with cognitive impairment due to possible dementing processes. Over $80 \%$ of older detainees were recommended to have a health assessment in police stations based on their presentation.

Police detainees over 50 should be considered to have a health assessment as routine procedure. Further investigation should also be conducted into cognitive impairment in this group. 


\section{Introduction}

As the UK ageing population expands so the number of older adults involved in the criminal justice system (CJS) is growing, with further growth predicted both in absolute terms and as a proportion of the whole prison population (Ministry of Justice/National Statistics, 2016). The older prison population has been well-described with increased numbers evident throughout the developed world (Fazel et al., 2001a; Collins and Bird, 2007; Moll, 2013) but there are little data available for other areas of the CJS, for example police detainees and offenders managed by probation and parole services. The health of police detainees is an important consideration; individuals may require medical attention whilst in custody (Payne-James et al., 2010), it may affect fitness to be detained (Ventress et al., 2008) or interviewed, and the presence of mental disorder may be relevant to the reason for arrest (Srivastava et al., 2013). It is not clear whether elderly detainees have greater health needs than their younger counterparts.

In the only empirical study of older police detainees in the UK, Needham-Bennett et al. (1996) interviewed 50 detainees aged 60 and over. The majority of alleged offences amongst older individuals were shoplifting (58\%), whilst $6 \%$ were arrested for a violent offence and $5 \%$ for a sexual offence. Most were men (72\%), married (52\%) and had no prior criminal record (58\%). Using the AGECAT (Copeland et al., 1986), 28\% were found to have a diagnosable mental disorder including four people with possible dementia. No relationship was found between the presence of mental disorder and later-onset criminal behaviour. In subsequent action by the police, $58 \%$ were cautioned, $38 \%$ had no further action taken, and $4 \%$ were prosecuted. Overall $28 \%$ were referred to a welfare agency, including just over one-half of those found to have a mental disorder.

Outside the UK, more data is available from France where Beaufrere and Chariot (2015) described the characteristics of 211 detainees over 60 who received a medical examination in Paris during 2012. Again, the sample was predominantly male (84\%) though the variation in offences was somewhat different; here only $7 \%$ of arrests concerned thefts or robberies while $40 \%$ were arrested 
for physical assaults, $14 \%$ for drunk driving and $7 \%$ for sexual offences. For $62 \%$ of these older detainees it was their first time in custody. The authors compared the older group with 18,751 people aged below 60 arrested in the same period, finding that older people were significantly more likely to have current physical and mental health disorders. Following review, 34 older detainees $(10 \%)$ were unfit to be detained, including $11(3 \%)$ who required immediate hospitalisation.

It is notable that these studies have defined elderly people as those 60 and above. There is some evidence that 50 may represent a more appropriate cut-off for people in the CJS. However there is a lack of consensus on the definition of older prisoners, and a range of ages from 45 to 60 years have been put forward (Yorston and Taylor, 2006; Baidawi et al., 2011). There is also data from prison studies that suggests that the health of prisoners aged 50-59 is similar to those aged over 60 , both being worse than the health of people aged over 60 in the community (Fazel et al., 2001b; Hayes et al., 2012). This remains a controversial area however, with no clear agreement on which is the apposite age cut off.

This paper reports secondary analysis of data collected as part of the "Health Screening of People in Police Custody" (HELP-PC) study (McKinnon and Grubin, 2014). Here, we describe the demographic and health characteristics of people aged 50 and over arrested in London, and compare them with those of younger detainees. 


\section{Method}

The study took place at three police stations in London over two discrete periods between 2009 and 2012. Detainees $>18$ years arrested under the Police and Criminal Evidence Act (1984) were eligible for inclusion. Researchers approached consecutive detainees for consent to complete a research questionnaire culminating in clinical decisions on the presence of a range of morbidities, including recommendations for review by a Health Care Professional (HCP). Detainees lacking capacity to consent were not interviewed, but the reason for incapacity was recorded (e.g. behavioural disturbance, cognitive problems etc.) Detainees were excluded if Custody Officers (COs) deemed it unsafe for them to be interviewed by the researcher, or if their grasp of English was insufficient to obtain consent. A full description of the methodology is published elsewhere (McKinnon and Grubin, 2013).

Researchers were present during working hours for seven-day periods (including weekends) covering a total of 127 days over the two research periods. The interview comprised a proforma to capture demographic characteristics, reason for current arrest, past psychiatric contact, and current medications, as well as the following:

- Mini International Neuropsychiatric Interview (MINI) for psychiatric diagnoses in the second period of data collection (Sheehan et al., 2004));

- Brief Psychiatric Rating Scale (BPRS) 18-item version for current psychiatric symptoms (Hafkenscheid, 1991). This included analysis of the five factor structures recommended by Overall and Beller (1984);

- CAGE questionnaire for alcohol misuse (Ewing, 1984);

- Severity of Dependence Scale for drug use (Gossop et al., 1995);

- Beck Scale for Suicide Ideation (Beck and Steer, 1993);

- A proforma to capture the presence of physical health conditions adapted from the Faculty of Forensic and Legal Medicine (Faculty of Forensic and Legal Medicine, 2007).

In addition to the CAGE questionnaire, a clinical history was obtained from each detainee, including patterns of drinking and recent alcohol consumption to ascertain the potential for alcohol 
withdrawal. At the end of each clinical interview, researchers were asked to make a clinical judgement as to whether each detainee needed the attention of a $\mathrm{HCP}$, based on their history and presentation. Researchers took into consideration the presence of any health disorders named in the Police and Criminal Evidence Act Code C (Home Office, 2014) or the police Standard Operating Procedures (Metropolitan Police Service, 2007).

Data were also collected on whether, based on the COs' initial screening, a referral was made to the HCP for each detainee. In the first period of data collection, COs used the standard "National Strategy for Police Information Systems" (NSPIS) risk assessment screen, embedded into the police computer system. In the second period, COs used the new HELP-PC risk assessment screen, which was intended to improve the detection of a range of health morbidities (McKinnon and Grubin, 2014). Unlike the HELP-PC screen, the NSPIS did not produce an overall screen positive or negative result. As a result, a proxy measure for the screening outcome was used over the two periods of data collection: following screening, was a HCP called (Yes indicating a screen positive, No indicating a screen negative.)

Additionally whilst the new HELP-PC risk assessment was being used, demographic data from every detainee entering custody were collected by the police, allowing a comparison between the population and the sample who we interviewed.

Clinical data were collected on paper forms which were entered onto SPSS version 19. SPSS and Minitab version 16 were used for analysis.

Both periods of data collection received ethical approval by Newcastle and North Tyneside Research Ethics Committee (08/H0906/130, 11/NE/0057). 


\section{Results}

Over the two periods of data collection, 1236 detainees were eligible for recruitment into the study. Police data on age, gender, ethnicity, offence type were available for all 1236 of these detainees. A total of $561(45 \%)$ were able to consent and underwent clinical interview. A further $26(2 \%)$ were unable to give consent due to behavioural disturbance, and $13(1 \%)$ because of cognitive difficulties. In all, information about the mental state of $600(49 \%)$ detainees was available. The remainder of the detainees fell into a number of categories including:

- 287 (23\%) who were unavailable to approach for consent as they were undergoing statutory police procedures at material time;

- 187 (15\%) who declined to take part having been approached for consent;

- 77 (6\%) who had insufficient grasp of English to understand the study information;

- $53(4 \%)$ who were judged to be 'too violent' by the CO;

- $18(2 \%)$ who were to intoxicated to give consent at the material time;

- $9(1 \%)$ who agreed but were released before the interview could begin;

- $5(0.5 \%)$ who required urgent medical treatment in hospital.

\section{Sample characteristics}

Those included in the study were similar in gender $\left[\chi^{2}(1)=0.416, p=0.519\right]$ to those not included. However, more people of 'White British' ethnicity and fewer of 'White Other' ethnicity were included in the study $\left[\chi^{2}(3)=20.1, p<0.001\right]$. There were marginally more people arrested forsexual offences in the sample compared to those not included [ $2.7 \%$ vs. $0.1 \%, 95 \% \mathrm{Cl}$ for difference: 0.4 to $3.3 \%]$., with no other differences in offence categories between the two groups.

Of the 1236 people arrested within the sampling window over the two data collection periods, 107 (8.7\%) were aged 50 and over. Of the 600 included in the study, 57 (9.5\%) were aged 50 and over. 
Similarly, age data available from the risk assessments of all 1180 detainees aged 18 and over during the second data period showed that a similar proportion were aged 50 or over [97 (8.2\%)].

Amongst older detainees there were no significant differences in those included or excluded from the study in gender, ethnicity or offence type [p>0.05].

\section{Offence type}

Demographic and offence type information of those included in the study is presented in Table 1, showing comparisons of those over and under age 50 . There were no significant differences between the age groups for gender $\left[\chi^{2}(1)=0.28, p=0.965\right]$, or ethnicity $\left[\chi^{2}(3)=4.30, p=0.231\right]$. Fewer older detainees had been arrested for an acquisitive offence than younger detainees [ $29.1 \% \mathrm{vs} .12 .3,95 \% \mathrm{Cl}$ for difference: 7 to $26 \%$ ]. An excess of older people arrested for violent offences did not quite reach statistical significance [ $40.3 \%$ vs. $27.2 \%, 95 \% \mathrm{Cl}$ for difference: -2 to $26 \%$ ].

\section{General health morbidity}

Health characteristics are shown in Table 2 . The older group had significantly higher rates of asthma $\left[\chi^{2}(1)=4.8, p=0.035\right]$, diabetes $\left[\chi^{2}(1)=12.8, p<0.001\right]$, hypertension $\left[\chi^{2}(1)=9.7, p=0.002\right]$, and current gastro-intestinal symptoms $\left[\chi^{2}(1)=17.8, p<0.001\right]$. They were also significantly more likely to be taking medication $\left[\chi^{2}(1)=19.2, p<0.001\right]$.

\section{Mental disorder}

Mean BPRS scores were 24.7 (SD 5.9) for the older group and 25.2 (SD 8.0) for younger detainees $p=0.468]$. There was no significant difference between the groups on total scores or those scoring above clinical cut-offs (a score of 4 or more) for each item. There were also no significant differences in those with serious mental illness or in past contact with psychiatric services. Analysis of the five primary item clusters revealed no differences between the two groups. 
Five (9\%) of the older detainees were judged to have possible organic cognitive impairment, compared to one $(0.2 \%)$ of the younger group (Fisher's exact test: $p<0.001)$. There were no differences between the older and younger group for any of the MINI diagnostic categories.

\section{Substance Misuse}

For alcohol, CAGE scores did not differ significantly between groups [0.8 vs $1 ; p=0.412$, and there were no differences when controlling for sex or ethnicity. However significantly more older detainees were judged to be at risk of alcohol withdrawal $[\chi 2(1)=3.9, p=0.049]$, comprising over a quarter of this group. This effect was more pronounced among male detainees $[\chi 2(1)=5.3, p=0.021]$, and among those of White British ethnicity, although the latter analysis did not reach statistical significance $[\chi 2(1)=3.2, p=0.074]$. There was no difference in the proportion with recent opiate or crack cocaine use [Fisher's exact $p=0.786$ and 0.102 respectively].

\section{Need for review by HCP}

The proportion of detainees judged by researchers to be in need of review by a custody HCP was significantly greater in the older group [ $\chi 2(1)=17.4, p<0.001]$; it was recommended that $46 / 57(81 \%)$ of those over 50 required further assessment compared to $288 / 543$ (53\%) in the younger group.

\section{Screening by the Custody Officer (CO)}

Of the 107 detainees who were 50 and over in the sampling window, 74 (69\%) were referred to the HCP by the CO, compared to 588 of the $1129(52 \%)$ detainees under $50[x 2(1)=11.5, p<0.001]$. 


\section{Discussion}

This paper summarises the demographic, health, and arrest characteristics of older people arrested by the police. Detainees aged 50 and over represented nearly $10 \%$ of those arrested. This compared to one German study where $11 \%$ of police detainees assessed by a physician were aged 51 and over, although this was not a sample all detainees entering custody (Heide et al., 2012). One study in the Netherlands found that $10 \%$ of randomly selected police detainees who took part in a health interview survey were over 50 years.

In our study, the older group had a higher level of physical morbidity but comparable rates of mental illness and substance misuse compared to younger detainees. Notably, five older detainees were thought to have a primary diagnosis of dementia leading to the incident for which they were arrested. Researchers recommended that the majority of older detainees (83\%) needed to be seen by a HCP compared to around half of the younger group. The reasons for researchers recommending referral to a HCP were diverse; these ranged from detainees disclosing single morbidities (e.g. uncomplicated asthma), to those who had multiple health problems and medications. COs also were more likely to screen the older detainees positive, but the proportion identified (69\%) fell short of the need judged by researchers across the two data collection periods.

The data showed an excess of older detainees at risk of alcohol withdrawal syndrome. Resources did not allow for this process to be formally assessed, but the clinical evidence available to researchers highlighted the need for further attention for these detainees. Overall over 4 out of 5 detainees over 50 were recommended to see a HCP for any reason.

Due to the high level of health need reported here, we recommend that all those over 50 should receive review by a HCP following arrest. The presence of older detainees with possible cognitive impairment suggests that this is an area where additional awareness among police staff may be required. Given that disinhibited behaviour can be an early feature of cognitive impairment 
(Starkstein et al., 2004; van Hooren and Waterwink, 2015), this presentation, especially among older detainees, should trigger a referral for psychiatric assessment and/or diversion where appropriate.

Previous UK data on older detainees demonstrated a somewhat different offence profile, with more $(63 \%)$ arrested for shoplifting and fewer for violent $(12 \%)$ and sexual $(10 \%)$ offences (NeedhamBennett et al., 1996). In the current study older detainees were arrested having been accused of fewer acquisitive and more violent offences than their younger counterparts. The reasons for this difference are unclear, and do not appear to represent the difference in age groups (the previous study having used 60 as an age cut-off); of 17 detainees aged 60 and over in this dataset, only one was arrested for an acquisitive offence while 8 were arrested for a violent offence. More likely is that police practices may have changed over the twenty years between the studies with more instances of older adults shoplifting being diverted from arrest by the police. Our data shows more similarity with the larger French sample reported by Beaufrere and Chariot (2015) where $40 \%$ of those over 60 were arrested for a suspected violent offence. The sample is also different to that of older adults in prison, where there is a preponderance of sexual offenders (Hayes et al., 2012).

This study included a clinical interview very soon after arrest so symptoms are likely to be valid in terms of the police caseload. There were no significant demographic differences between the older arrestees interviewed and those not interviewed, suggesting the interviewed sample are likely to be representative of all older people in police custody seen in the samples presented here.

There are a number of limitations to the study. Less than one-half of police detainees were included in the study overall, reflecting some of the methodological difficulties of carrying out this kind of research in police custody suites. The number of older detainees was small, and may also reflect the characteristics of the area in London where the arrests took place rather than being generalizable to older detainees elsewhere, as well as limiting the power of some of the comparative tests. Criminal history was not available so it was not possible to establish whether detainees had prior contact with the CJS or were first time in police custody in older age; we cannot, therefore, compare our results 
with those of Needham-Bennett et al. (1996) who found that there was no relationship between mental disorder and later-life offending. Finally, data collection took place within extended "office hours" (8am to midnight). Consequently, although detainees attending the police station at night were included if they remained in custody the following morning, others who were arrested and released overnight were missed, and it is possible the latter group differ from those included here.

We recommend that large scale studies focussed on older detainees in police custody take place, to better describe the nature of alleged offences, morbidities, and outcomes for this vulnerable group. 


\section{Declaration of Sources of Funding}

The study was supported by a National Institute for Health Research (NIHR) Doctoral Research Fellowship to IM (DRF-2010-03-95) and funding to IM and DG obtained by Northumberland Tyne and Wear NHS Foundation Trust. The views expressed are those of the authors and not necessarily those of the NHS, the NIHR or the UK Department of Health.

\section{Conflicts of interest}

Other than the funding described above, the authors have no further conflicts of interest to declare. 


\section{Tables}

Table 1: Demographics and Offence Characteristics

\begin{tabular}{|c|c|c|c|c|c|c|}
\hline & & \multicolumn{2}{|c|}{ Age $<50$} & \multicolumn{2}{|c|}{ Age 50+ } & \multirow{2}{*}{$\begin{array}{l}\text { Statistical } \\
\text { Difference }\end{array}$} \\
\hline & & $\mathrm{N}$ & $\%$ & $\mathrm{~N}$ & $\%$ & \\
\hline \multirow[t]{2}{*}{ Gender } & Male & 471 & 86.7 & 48 & 84.2 & \multirow[t]{2}{*}{ nd } \\
\hline & Female & 72 & 13.3 & 9 & 15.8 & \\
\hline \multirow{4}{*}{$\begin{array}{l}\text { Ethnicity } \\
* *\end{array}$} & White British & 223 & 41.4 & 31 & 54.4 & \multirow[t]{4}{*}{ nd } \\
\hline & White Other & 85 & 15.8 & 8 & 14.0 & \\
\hline & Other British & 127 & 23.6 & 8 & 14.0 & \\
\hline & Other & 104 & 19.3 & 10 & 17.5 & \\
\hline \multirow[t]{11}{*}{ Offence } & Violent & 148 & 27.3 & 22 & 38.6 & \multirow[t]{11}{*}{$*$} \\
\hline & Sexual & 16 & 2.9 & 0 & 0 & \\
\hline & Drug & 44 & 8.1 & 3 & 5.3 & \\
\hline & Acquisitive & 158 & 29.1 & 7 & 12.3 & \\
\hline & Driving & 18 & 3.3 & 1 & 1.8 & \\
\hline & Fraud & 24 & 4.4 & 2 & 3.5 & \\
\hline & Unknown & 33 & 6.1 & 3 & 5.3 & \\
\hline & Weapon & 8 & 1.5 & 2 & 3.5 & \\
\hline & Public Order/Criminal Damage & 60 & 11 & 10 & 17.5 & \\
\hline & Other & 23 & 4.2 & 3 & 5.3 & \\
\hline & Breach & 11 & 2 & 4 & 7 & \\
\hline
\end{tabular}

$* \mathrm{p}<0.05 \quad * *$ Ethnicity not stated in 4 cases 


\begin{tabular}{|l|c|c|c|c|l|}
\hline \multirow{2}{*}{} & \multicolumn{2}{|c|}{ Age $<50$} & \multicolumn{2}{c|}{ Age 50+ } & \multirow{2}{*}{$\begin{array}{l}\text { Statistical } \\
\text { Difference }\end{array}$} \\
\cline { 2 - 6 } & $\mathrm{N}$ & $\%$ & $\mathrm{~N}$ & $\%$ & $*$ \\
\hline Asthma & 67 & 13.1 & 12 & 24.5 & $*$ \\
\hline Diabetes & 13 & 2.5 & 6 & 12.2 & $* * *$ \\
\hline Epilepsy & 10 & 2 & 1 & 2 & \\
\hline Hypertension & 32 & 6.3 & 9 & 18.4 & $* *$ \\
\hline Blood-Borne Virus & 12 & 2.4 & 2 & 4.1 & \\
\hline Cardiovascular symptoms & 67 & 13.2 & 9 & 18.4 & \\
\hline Gastro-intestinal symptoms & 84 & 17 & 19 & 43.2 & $* * *$ \\
\hline Any medication & 180 & 35.5 & 33 & 67.3 & $* * *$ \\
\hline At risk of alcohol withdrawal & 71 & 14.6 & 12 & 26.1 & $*$ \\
\hline Opiate use & 42 & 8.6 & 3 & 6.5 & \\
\hline Cocaine use & 65 & 13.3 & 2 & 4.3 & \\
\hline Past psychiatric contact & 45 & 8.8 & 3 & 6.1 & \\
\hline Past psychiatric admission & 23 & 4.5 & 1 & 2 & \\
\hline GP registration & 429 & 82.7 & 46 & 92 & \\
\hline Reviewby HCP Recommended. & 288 & 53 & 46 & 82.1 & $* * *$ \\
\hline
\end{tabular}

${ }^{*} p<0.05-{ }^{* *} p<0.01-{ }^{* * *} p<0.001$ 


\section{References}

Baidawi, S., Turner, S., Trotter, C., Browning, C., Collier, P., O'Connor, D. and Sheehan, R. (2011) Older prisoners $-A$ challenge for Australian corrections. Canberra, ACT, Australia: Australian Institute of Criminology Criminology, A.I.o.

Beaufrere, A. and Chariot, P. (2015) 'The health of older arrestees in police cells', Age Ageing, 44(4), pp. 662-7.

Beck, A.T. and Steer, R.A. (1993) Beck Scale For Suicide Ideation. Manual. San Antonio, Tx, USA: Pearson.

Collins, D.R. and Bird, R. (2007) 'The penitentiary visit--a new role for geriatricians?', Age Ageing, 36(1), pp. 11-3.

Copeland, J.R., Dewey, M.E. and Griffiths-Jones, H.M. (1986) 'A computerized psychiatric diagnostic system and case nomenclature for elderly subjects: GMS and AGECAT', Psychol Med, 16(1), pp. 8999.

Ewing, J.A. (1984) 'Detecting alcoholism. The CAGE questionnaire', JAMA, 252(14), pp. 1905-7. Faculty of Forensic and Legal Medicine (2007) Proforma: Fitness for detention and interview. Available at: http://fflm.ac.uk/upload/documents/1194536634.pdf (Accessed: 25 July 2011). Fazel, S., Hope, T., O'Donnell, I. and Jacoby, R. (2001a) 'Hidden psychiatric morbidity in elderly prisoners', Br J Psychiatry, 179, pp. 535-9.

Fazel, S., Hope, T., O'Donnell, I., Piper, M. and Jacoby, R. (2001b) 'Health of elderly male prisoners: worse than the general population, worse than younger prisoners', Age Ageing, 30(5), pp. 403-7. Gossop, M., Darke, S., Griffiths, P., Hando, J., Powis, B., Hall, W. and Strang, J. (1995) 'The Severity of Dependence Scale (SDS): psychometric properties of the SDS in English and Australian samples of heroin, cocaine and amphetamine users', Addiction, 90(5), pp. 607-14.

Hafkenscheid, A. (1991) 'Psychometric evaluation of a standardized and expanded Brief Psychiatric Rating Scale', Acta Psychiatrica Scandinavica, 84(3), pp. 294-300.

Hayes, A.J., Burns, A., Turnbull, P. and Shaw, J.J. (2012) 'The health and social needs of older male prisoners', International Journal of Geriatric Psychiatry, 27(11), pp. 1155-1162.

Heide, S., Stiller, D., Lessig, R., Lautenschlager, C., Birkholz, M. and Fruchtnicht, W. (2012) 'Medical examination of fitness for police custody in two large German towns', Int J Legal Med, 126(1), pp. 2735.

Home Office (2014) Police and Criminal Evidence Act 1984 Code C. London, UK: The Home Office. McKinnon, I. and Grubin, D. (2014) 'Evidence-Based Risk Assessment Screening in Police Custody: The HELP-PC Study in London, UK', Policing: A Journal of Policy and Practice, 8(2), pp. 174-82.

McKinnon, I.G. and Grubin, D. (2013) 'Health screening of people in police custody--evaluation of current police screening procedures in London, UK', Eur J Public Health, 23(3), pp. 399-405.

Metropolitan Police Service (2007) MPS Custody Standard Operating Procedures. Version 3. London, UK: Metropolitan Police Service. [Online]. Available at: www.met.police.uk.

Ministry of Justice/National Statistics (2016) Prison Population Projections 2016-2021 England and Wales. London, UK: Ministry of Justice. [Online]. Available at:

https://www.gov.uk/government/uploads/system/uploads/attachment data/file/548271/prisonpopulation-projections-2016-2021.pdf (Accessed: 26 August 2016).

Moll, A. (2013) Losing track of time. Dementia and the ageing prison population: treatment challenges and examples of good practice. London, UK: Mental Health Foundation.

Needham-Bennett, H., Parrott, J. and MacDonald, A.J.D. (1996) 'Psychiatric disorder and policing the elderly offender', Criminal Behaviour and Mental Health, 6(3), pp. 241-252.

Overall, J.E. and Beller, S.A. (1984) 'The Brief Psychiatric Rating Scale (BPRS) in geropsychiatric research: I. Factor structure on an inpatient unit', J Gerontol, 39(2), pp. 187-93.

Payne-James, J.J., Green, P.G., Green, N., McLachlan, G.M., Munro, M.H. and Moore, T.C. (2010)

'Healthcare issues of detainees in police custody in London, UK', J Forensic Leg Med, 17(1), pp. 11-7. 
Sheehan, D., Janavs, J., Baker, R., Harnett-Sheehan, K., Knapp, E., Sheehan, M., Lecrubier, Y., Weiller, E., Hergueta, T., Amorim, P., Bonora, L.I. and Lépine, J.P. (2004) Mini International Neuropsychiatric Interview (M.I.N.I.) English Version 5.0.0 DSM-IV. Tampa, FL, USA.: Sheehan DV \& Lecrubier Y.

Srivastava, S., Forrester, A., Davies, S. and Nadkarni, R. (2013) 'Developing criminal justice liaison and diversion services: Research priorities and international learning', Criminal Behaviour and Mental Health, 23(5), pp. 315-320.

Starkstein, S.E., Garau, M.L. and Cao, A. (2004) 'Prevalence and clinical correlates of disinhibition in dementia', Cogn Behav Neurol, 17(3), pp. 139-47.

van Hooren, S. and Waterwink, W. (2015) 'Uncontrolled Sexual Behaviour in Dementia', in Zerr, I. (ed.) Alzheimer's Disease - Challenges for the Future. Online: InTech.

Ventress, M.A., Rix, K.J.B. and Kent, J.H. (2008) 'Keeping PACE: fitness to be interviewed by the police', Advances in Psychiatric Treatment, 14, pp. 369-381.

Yorston, G.A. and Taylor, P.J. (2006) 'Commentary: older offenders--no place to go?', J Am Acad Psychiatry Law, 34(3), pp. 333-7. 